\title{
Young People's Preparedness for Adult Life and Coping After Foster Care: A Systematic Review of Perceptions and Experiences in the Transition Period
}

\author{
Arja Häggman-Laitila ${ }^{1,2}$ (D) $\cdot$ Pirkko Salokekkilä $^{2} \cdot$ Suyen Karki ${ }^{1}$
}

Published online: 22 March 2019

(C) The Author(s) 2019

\begin{abstract}
Background The transition to adult life for those leaving foster care is a multidimensional phase of their personal development. Care leavers' life outcomes are poorer in education, employment, income, housing and parenthood compared with their peers from the general population. They suffer more than other youngsters from mental health and behavioral problems, substance abuse and involvement with criminality.

Objective This study aims to gather, assess and synthesize the current empirical evidence about subjective perceptions and experiences of former youth in foster care regarding their independent living during the transition to adulthood.

Method A systematic review was conducted of studies drawn from six databases and included quantitative studies from 2010 to 2017. Of the 37 eligible studies identified, 13 were selected for final review. Data was analyzed using a narrative method.

Results Foster care leavers identified themselves as adult and were quite confident about their future and potential for independent living. They had different coping strategies and profiles, but often faced the same challenges in finding employment, education and having a person whom they could rely on. Among the factors that supported the transition to independent living were care leavers' personal characteristics, certain care-specific features, good education, sufficient prerequisites for a safe life and social support.

Conclusions This review looked at various descriptive studies based on different conceptual perspectives, cultural contexts and methodologies. The evidence, however, still remains relatively insubstantial. Further studies are needed to provide more reliable evidence-based recommendations to inform service development, staff education and additional research activities.
\end{abstract}

Keywords Leaving care - Transition to adulthood - Preparedness for adult life · Coping · Independent living $\cdot$ Systematic review

Arja Häggman-Laitila

arja.haggman-laitila@uef.fi

1 Department of Nursing Science, University of Eastern Finland, P.O. Box 1627, 70211 Kuopio, Finland

2 City of Helsinki, Department of Social Services and Health Care, Toinen linja 4 A, P.O. Box 6000 , 00099 City of Helsinki, Finland 


\section{Introduction}

Youths leaving foster care between the ages of 18 and 21 experience a transition to adult life which is more complicated than for young people raised by their biological parents. The former have to take care of themselves independently earlier than their peers. In many cases, care leavers cannot rely on their biological parents for emotional, social, practical or financial support (Paulsen and Berg 2016; Rutman and Hubberstey 2016). Similarly, care leavers may avoid being close to people due to their negative experiences in relationships. Care leavers value relationships if there is trust, honesty, longevity and consistency (Hiles et al. 2013). Therefore, the characteristics of social networks, for instance, stronger ties, size or composition of support networks, network cohesion and centralization have impact on successfulness of transition to the adulthood (Blakeslee 2012).

Care leavers' transition to adult life is a multidimensional phase of their personal development and is shaped by their past experiences of vulnerability, their personal strengths, the levels of support they have received, possible problematic outcomes and the challenges they face in becoming self-sufficient (Courtney et al. 2012; Keller et al. 2007). Recent systematic reviews (Cameron et al. 2018; Gypen et al. 2017; Kääriälä and Hiilamo 2017) describing the well-being and health of former youth in foster care correspond closely to the results of previous reviews and studies (Berlin et al. 2011; Dumaret et al. 2011; Havlicek et al. 2013). In spite of differences in welfare systems of different countries, internationally it is the case that care leavers' outcomes are poorer in education, employment, income, housing and teenage parenthood than their counterparts' outcomes in the general population. They suffer more often from mental health and behavioral problems, substance abuse and involvement in criminality. Also, the rate of mortality and disability pensions is higher compared with their peers from the general population. Poor outcomes tend to accumulate in the lives of these young people, and their vulnerability in adult life is high. The common conclusions of the reviews (Cameron et al. 2018; Gypen et al. 2017; Kääriälä and Hiilamo 2017) are that foster care based both on the child protection and family services approach should be further developed to better meet care leavers' complex support needs.

Two decades ago, Stein (2006) suggested that within the resilience framework young people leaving care were divided into three groups: "moving on", "survivors" and "victims". The first group left the care later and their independent living was planned. They were able to secure their lives through increased confidence and self-esteem. They felt normal and accepted the challenges for independent living and had maintained positive relationships with others. The second group, the "survivors", left the care early as they experienced many difficulties and disruptions during care. This group had few or no qualifications and problems in securing homes and jobs. Further, they experienced problems in relationships. However, this group was able to cope and felt self-dependent despite they receive assistance for money, home and other personal assistance. The third group, the "victims", had come across more difficulties due to past family experiences. Further, they were placed in several care homes and had their education and personal relationships disrupted. They were more likely to have problems in their life such as being homeless and unemployed.

Two recent systematic reviews (Häggman-Laitila et al. 2018; Parry and Weatherhead 2014), which described 30 qualitative studies of care leavers' experiences of their transition to adult life complement the results of Stein's (2006) research review. In both reviews, the care leavers' views of their transition differed clearly based on their subjective experiences, capabilities, emotions and identity. Two groups of young people were identified. The first 
are those who experienced their transition as a possibility for a new beginning of life (Häggman-Laitila et al. 2018). They were self-confident, had positive future expectations and had the inner strength to build a better daily life and identity for themselves; they thus had a growing sense of hope. Parry and Weatherhead (2014) described these care leavers as youngsters whose resilience is increasing. They had learnt from their past experiences and could enhance their strengths. The second group of young people consisted of those who described the transition as a negative change in their life situation (Häggman-Laitila et al. 2018). They felt insecure about their future, received no support in dealing with the challenges of daily living, were socially isolated and had constant housing problems. Therefore, they had many fears and were lonely. In addition, they were uncertain about their identity and faced negative judgments from others. Parry and Weatherhead (2014) described these young people as persons who had gotten lost in the system, and characterized care leavers' anxiety, grief and humor as a survival skill. They also provided specified categorizations of care leavers' identities.

The process of leaving foster care was described in the reviews mainly as unplanned and unfocused, with a marked lack of support from care providers, immediate birth family and institutional bodies (Häggman-Laitila et al. 2018; Parry and Weatherhead 2014). Leaving care provided youth in foster care with no opportunities for participating in the decisionmaking concerning their future (Häggman-Laitila et al. 2018). When young people had received successful formal and informal support in their transition process to independent living, it was experienced as empowering (Häggman-Laitila et al. 2018; Parry and Weatherhead 2014). The challenges young people often faced during the transition to independent living were concerned with academic qualifications, housing, employment and financial stability, building relationships, making adjustments to cultural norms and using health services (Häggman-Laitila et al. 2018).

Vulnerable people's involvement in the welfare systems has been recognized as an important ethical challenge. Studies describing vulnerable people's experiences as service users have formulated an evidence-based approach to the development of a customerfocused welfare system. As many studies have highlighted that the transition outcomes for care leavers are poor, understanding the care leavers' experiences and perceptions of their transition period to adult life helps to develop evidence-based service models or interventions from their perspective. To supplement the results of the qualitative systematic reviews (Häggman-Laitila et al. 2018; Parry and Weatherhead 2014) of care leavers' transition period, we wanted to conduct a systematic review of quantitative studies on same topic. The knowledge that has resulted from these quantitative studies carried out in different countries is scattered and fragmented. The reviews and synthesis of research knowledge are needed to provide evidence-based recommendations to inform policy makers, services and future research. To understand more deeply the development needs of foster care services (Cameron et al. 2018; Gypen et al. 2017; Kääriälä and Hiilamo 2017), it is important to provide up-to-date and comprehensive information how contemporary young people have experienced their transition to adult life after foster care.

\section{Aim and Research Questions}

The aim of the review is to gather, assess and synthesize the current empirical evidence about subjective perceptions and experiences of former youth in foster care regarding their independent living during the transition to adulthood. Specifically, the following research questions were set for the review: 
1. How do care leavers assess their preparedness for independent living?

2. What kind of support needs do they have?

3. What kind of experiences do they have of coping in the transition phase to adulthood?

\section{Method}

\section{Design}

A systematic review was conducted based on the procedure devised by the Centre for Reviews and Dissemination (2009) and the PRISMA statement (Moher et al. 2009) for the identification, assessment and synthesis of quantitative research.

\section{Databases, Search Terms and Inclusion Criteria}

A systematic literature search was carried out using six databases and several search terms (Table 1). The search covered the period from 1 January 2010 to 31 December 2017. Details of the study identification and selection process are shown in a PRISMA flow chart (Moher et al. 2009) (Fig. 1). Initially, the search was conducted without any limitations. As Scopus and PsycInfo both provided large numbers of hits, we applied search limitations such as title, keywords, abstract, original articles (limited to the English language only) in Scopus and peer-reviewed articles only in PyscInfo. Inclusion criteria for the original articles are described in Table 1.

\section{Search Outcome and Exclusion Criteria}

The search outcome $(\mathrm{n}=1622)$ was transferred to RefWorks and duplicates were removed. Papers that were not empirical studies - systematic reviews, reports of development projects or contemporary issues, such as descriptions of child welfare policies and service systems or advertisements for new publications-were excluded. Papers were also excluded on the basis that the participants were still in foster care, the participants were elderly people receiving residential care or were employees or family members of looked-after children or young persons. Articles describing leaving services other than foster care, for example services for alcohol or drug addiction, imprisoned persons or mental health patients and disabled or mentally challenged young people, were also excluded.

After removing duplicate items, two authors screened the titles and abstracts of 982 hits based on the inclusion and exclusion criteria, and selected 219 studies for further full-text reading. Full-text reading led to 140 eligible studies, which included 53 quantitative, 28 intervention and 59 qualitative studies. The data were analyzed separately and are reported in three systematic reviews. In the present review, we have chosen to include the studies that used quantitative methods and were published from 2010 to 2017; this time frame was chosen to provide up-to-date data for the development of professional services. After thorough reading of the eligible studies $(n=37), 13$ were selected for final review. In this final selection phase (Fig. 1) the articles that were excluded concerned intervention, care systems, evaluation studies, drug abuse, parenting relationships, parents or teacher perception, preparation to leave care, homelessness, mental health diagnosis, special residential care, 


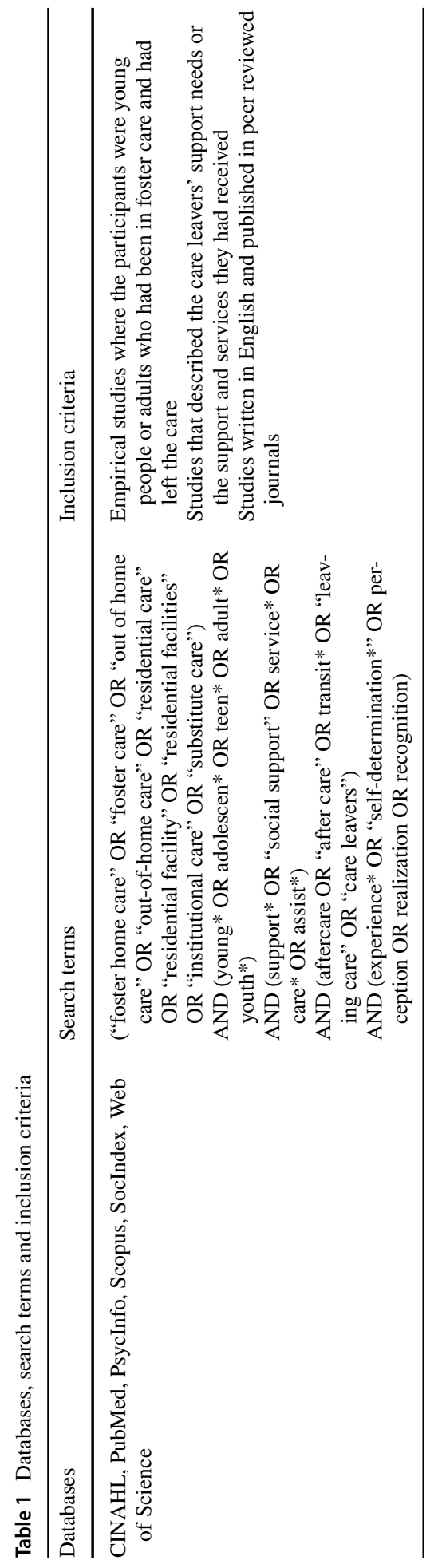




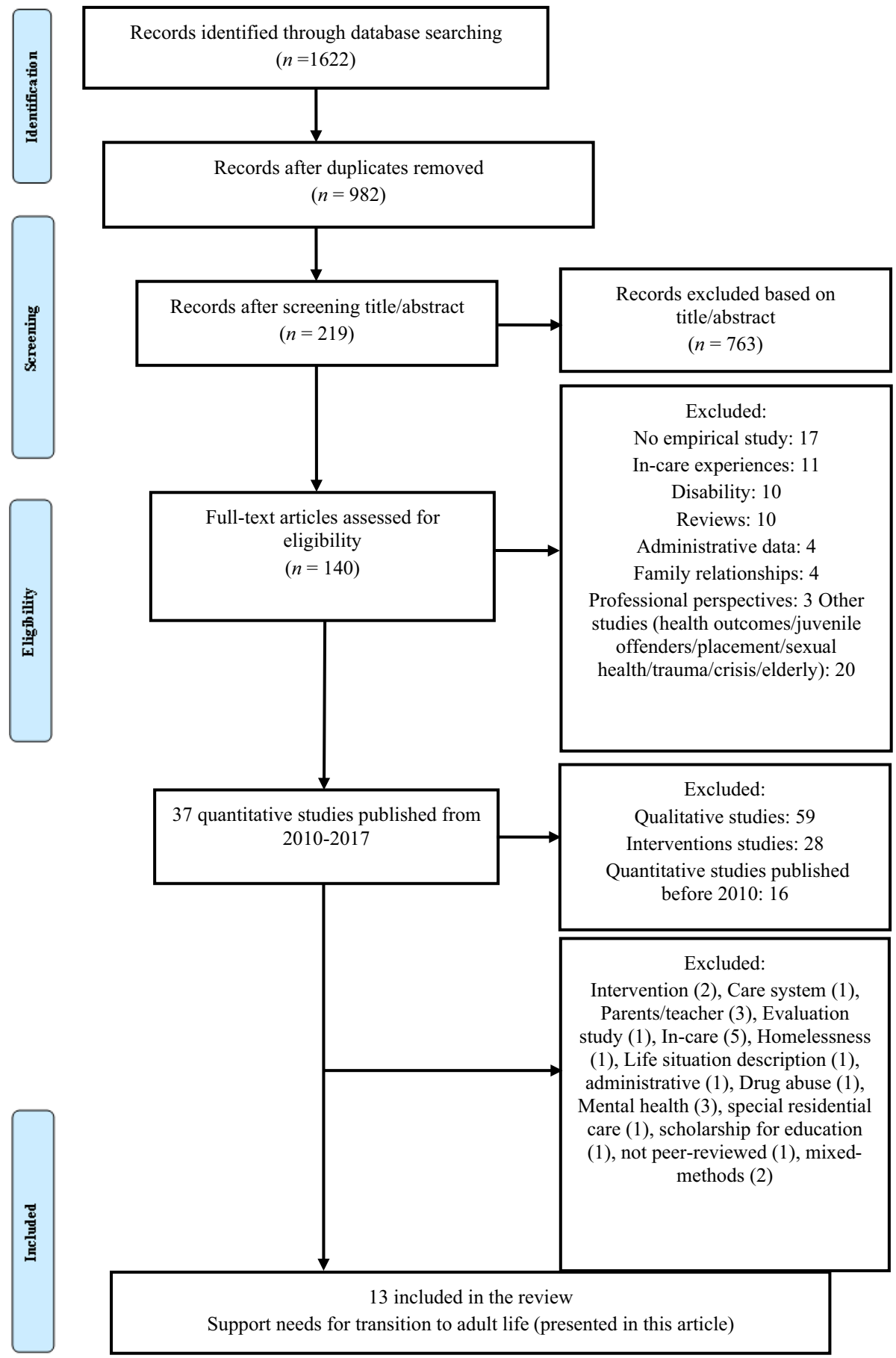

Fig. 1 Prisma flow chart for selection of articles 
scholarships provided and dis/engagement from/with further education, descriptions of life situation, mixed-methods and perception or preparation in-care.

\section{Quality Appraisal}

The quality of the included studies was checked independently by two authors using a critical appraisal of a cross-sectional study (survey) (Center for Evidence-Based Management 2014) (Table 2). It consists of 12 appraisal questions with the following evaluation options: yes, can't tell and no. The two authors compared their evaluations and made their final decisions on the appraisal based on the comparison. No disagreement emerged at this point. The quality of the studies was mainly good, varying mostly on criteria concerning sample selection and size, validity and reliability of measurements, presentation of confidence intervals and accounting for confounding factors. None of the studies were excluded based on the quality appraisal.

\section{Data Abstraction and Synthesis}

Data were extracted from each study and placed in a matrix, including the aim of the study, participants, study design, methods and results (Table 3). The information in the matrix was analyzed using a narrative method (Centre for Reviews and Dissemination 2009). Two authors read through the selected articles repeatedly until their contents were understood. The information in the matrix was reduced to a set of simplified expressions. The expressions were compared: those with similar content were grouped together, arranged into different themes based on their content and named accordingly. The themes were considered according to the research questions and grouped into a narrative synthesis of the experiences of former foster care youth. Two authors conducted the analysis and came to a mutual understanding of the narrative synthesis, which is presented in the text and in Table 4.

\section{Results}

Almost all of these studies were conducted in United States, notable exceptions being three in Israel and one in India. The total number of participants from the selected studies was 3502 (1393 male, 1525 females; the gender of 584 participants was not reported in Courtney et al. 2012) with mean age ranging from 16.95 to 22.16 years. Further, in the studies that were conducted in the United States various ethnic groups were included, such as Caucasian, African American, Asian American, European-American, Hispanic, Native American, Pacific Islander and multiethnic. The Indian study included various religious groups, e.g. Hindus, Buddhists, Muslims, Christians and others. In the Israel studies, participants were native Israelis, Ethiopians, Russians and others (see Table 3).

Ten of these studies collected data using interviews (Casey et al. 2010; Courtney et al. 2012; Dutta 2017; Fowler et al. 2011; Grey et al. 2015; Melkman 2017; Singer and Berzin 2015; Sulimani-Aidan 2015; Tyrell and Yates 2016; Zinn et al. 2017). More particularly, one study used group interviews (Casey et al. 2010), four studies used face-to-face interviews (Dutta 2017; Grey et al. 2015; Melkman 2017; Tyrell and Yates 2016) and two used telephone interviews (Sulimani-Aidan 2015; Fowler et al. 2011). Further, four studies used self-reported questionnaires (Dinisman and Zeira 2011; Huscroft-D’Angelo et al. 2013; 


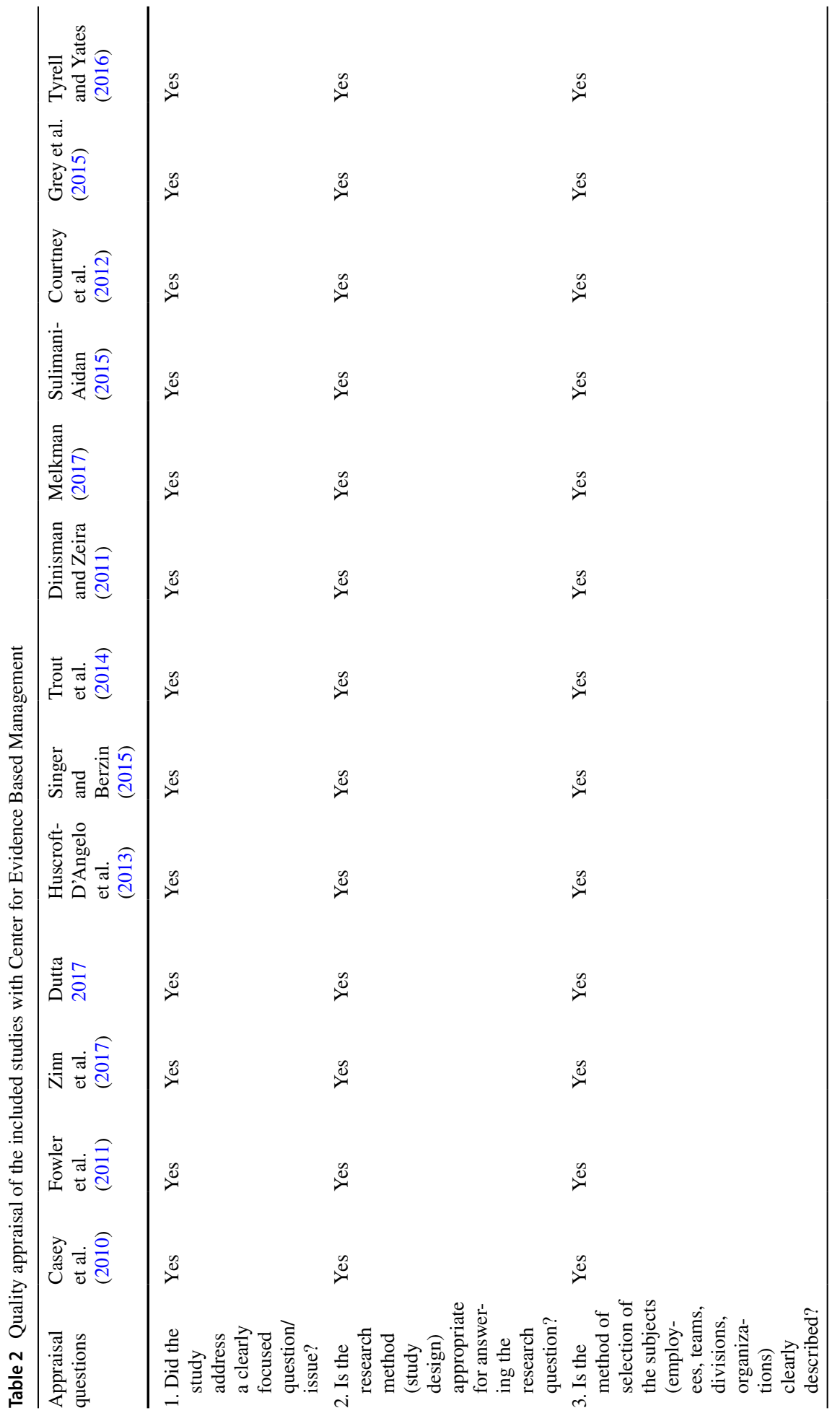




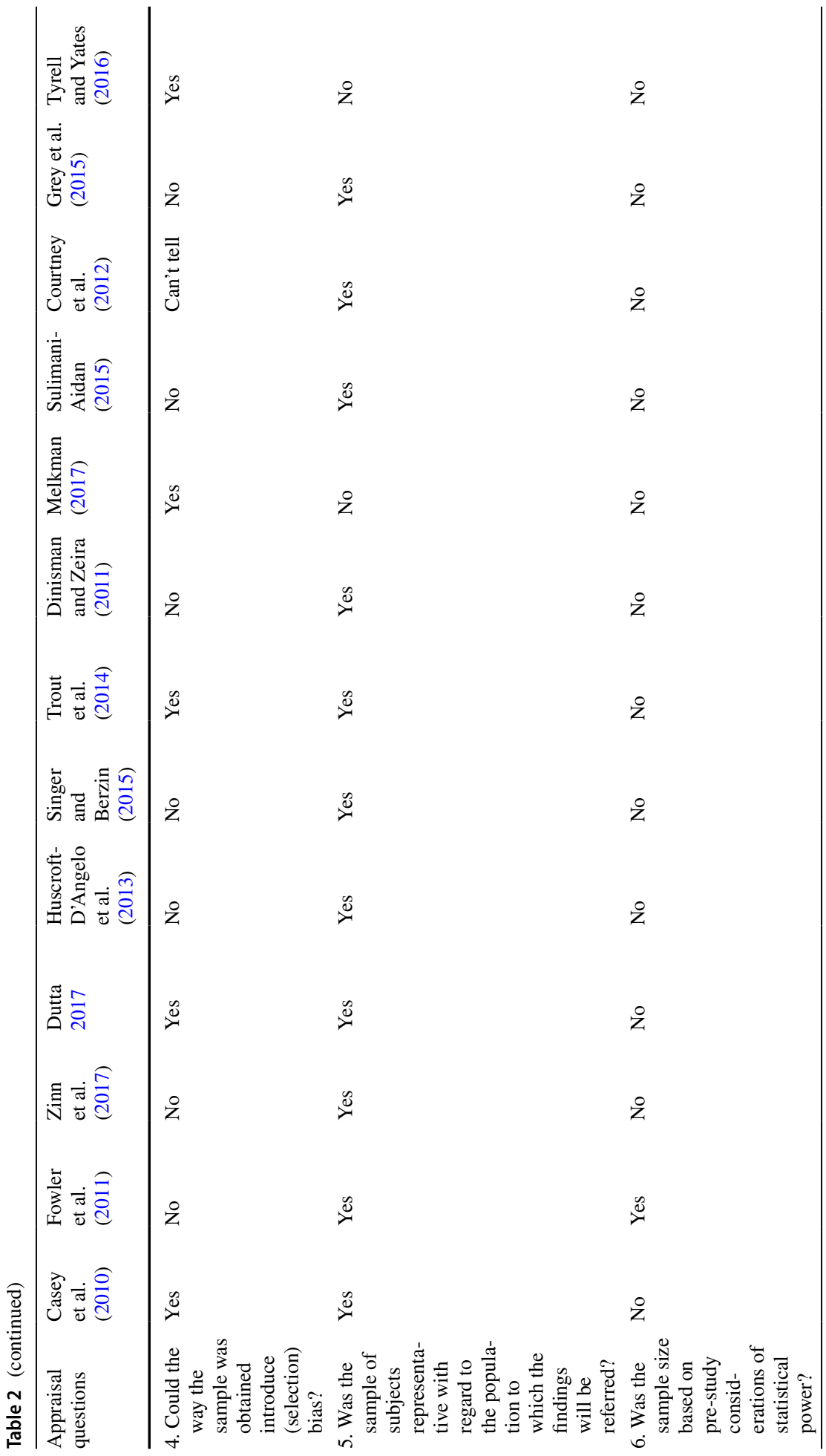




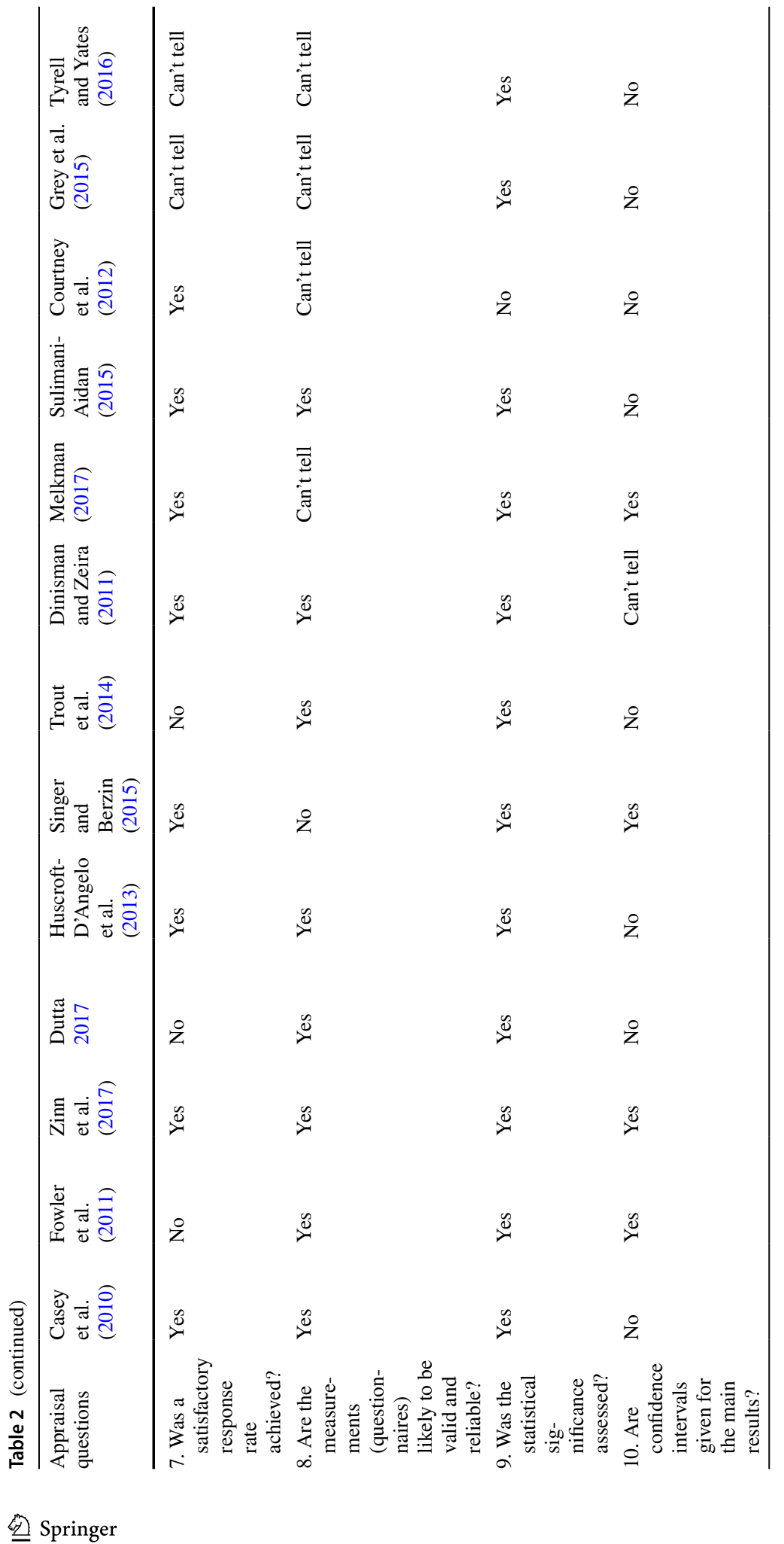




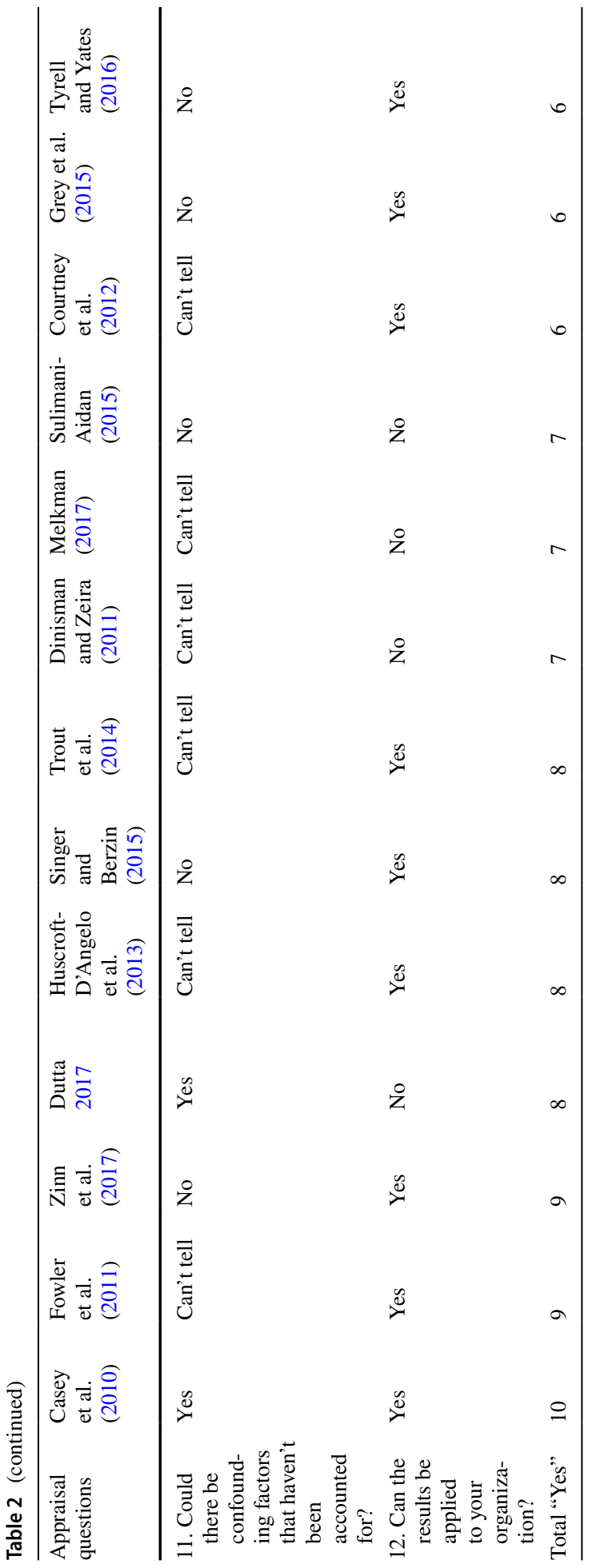




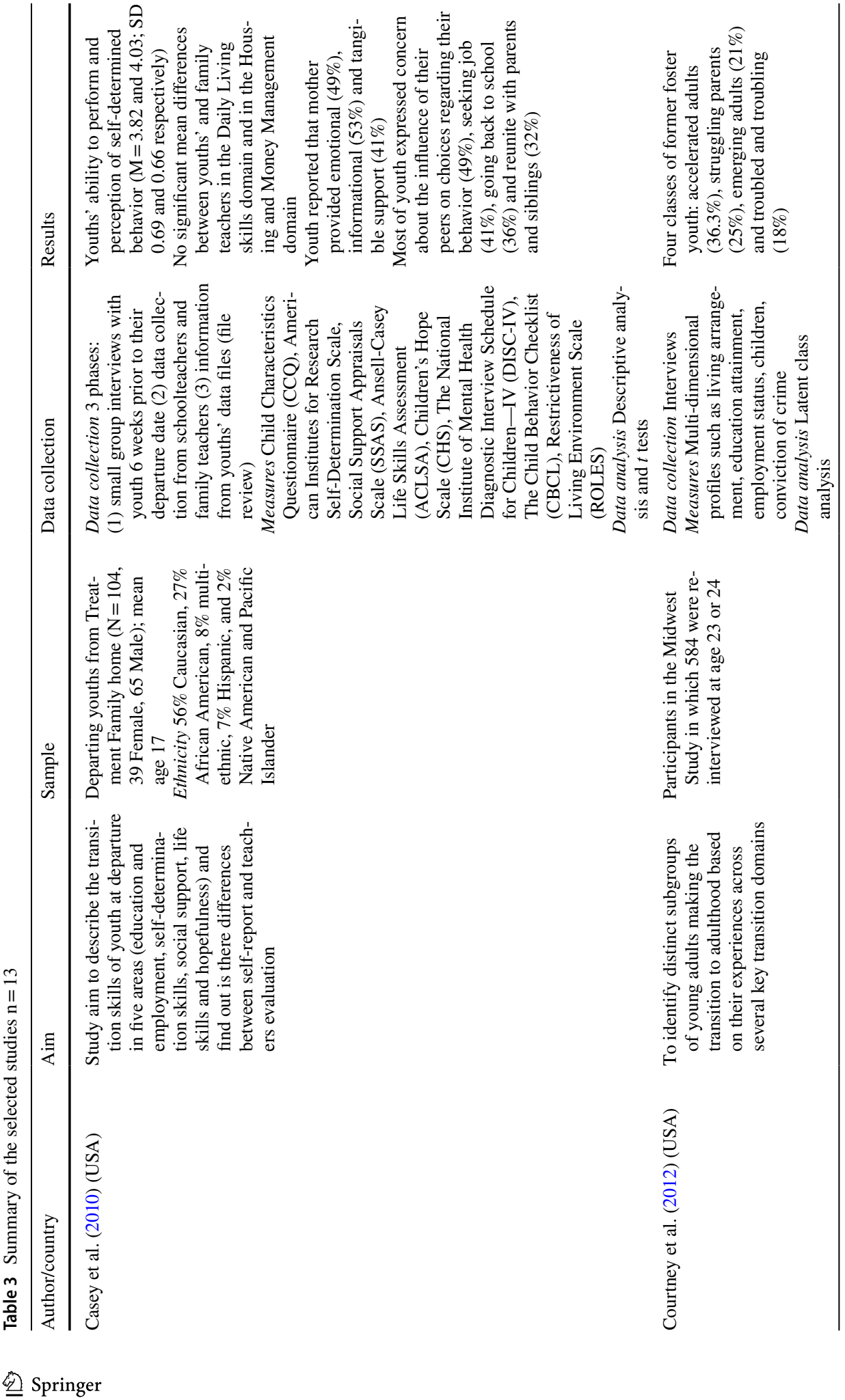




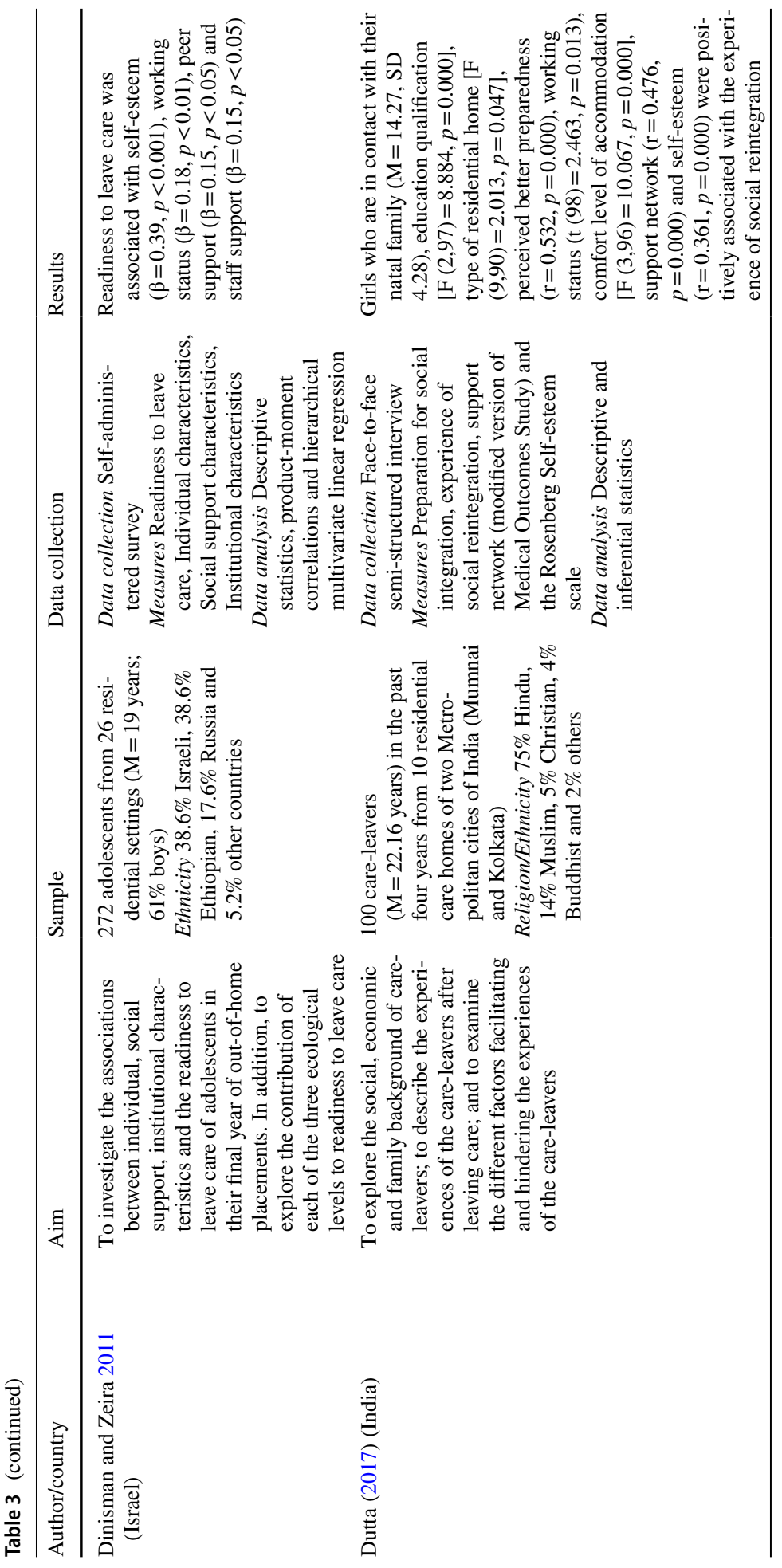




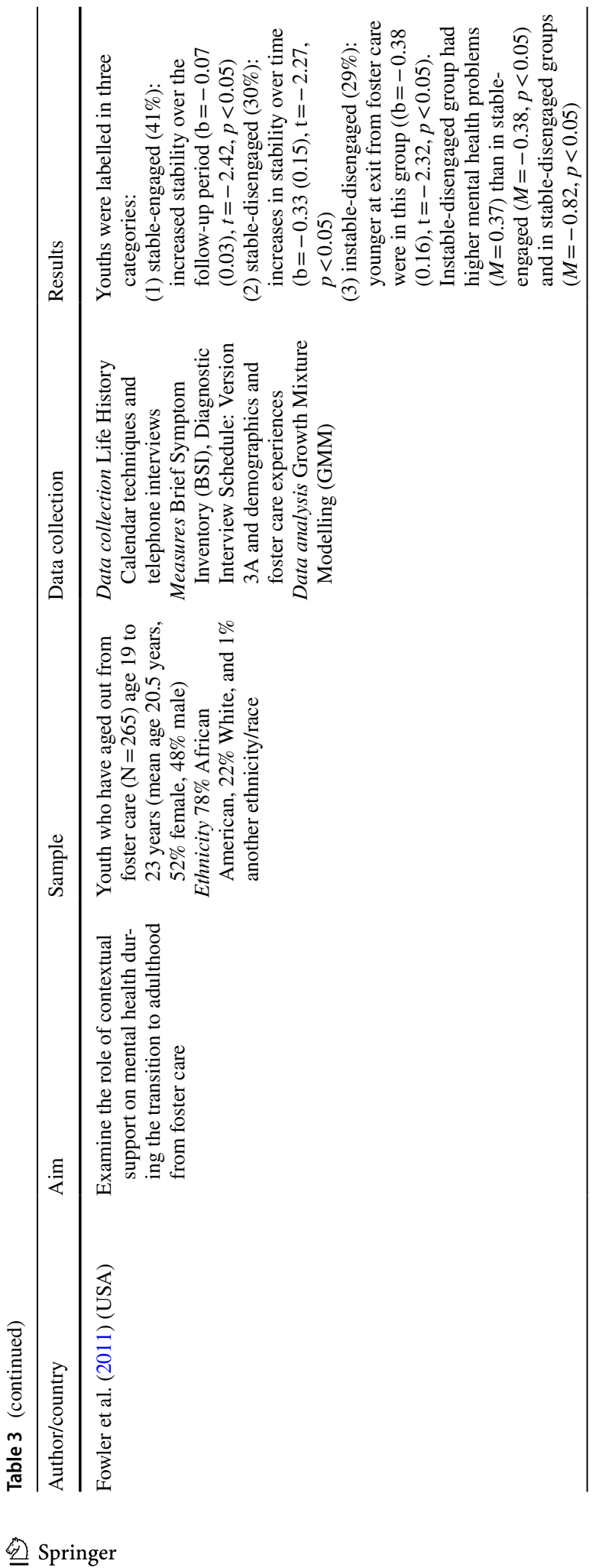




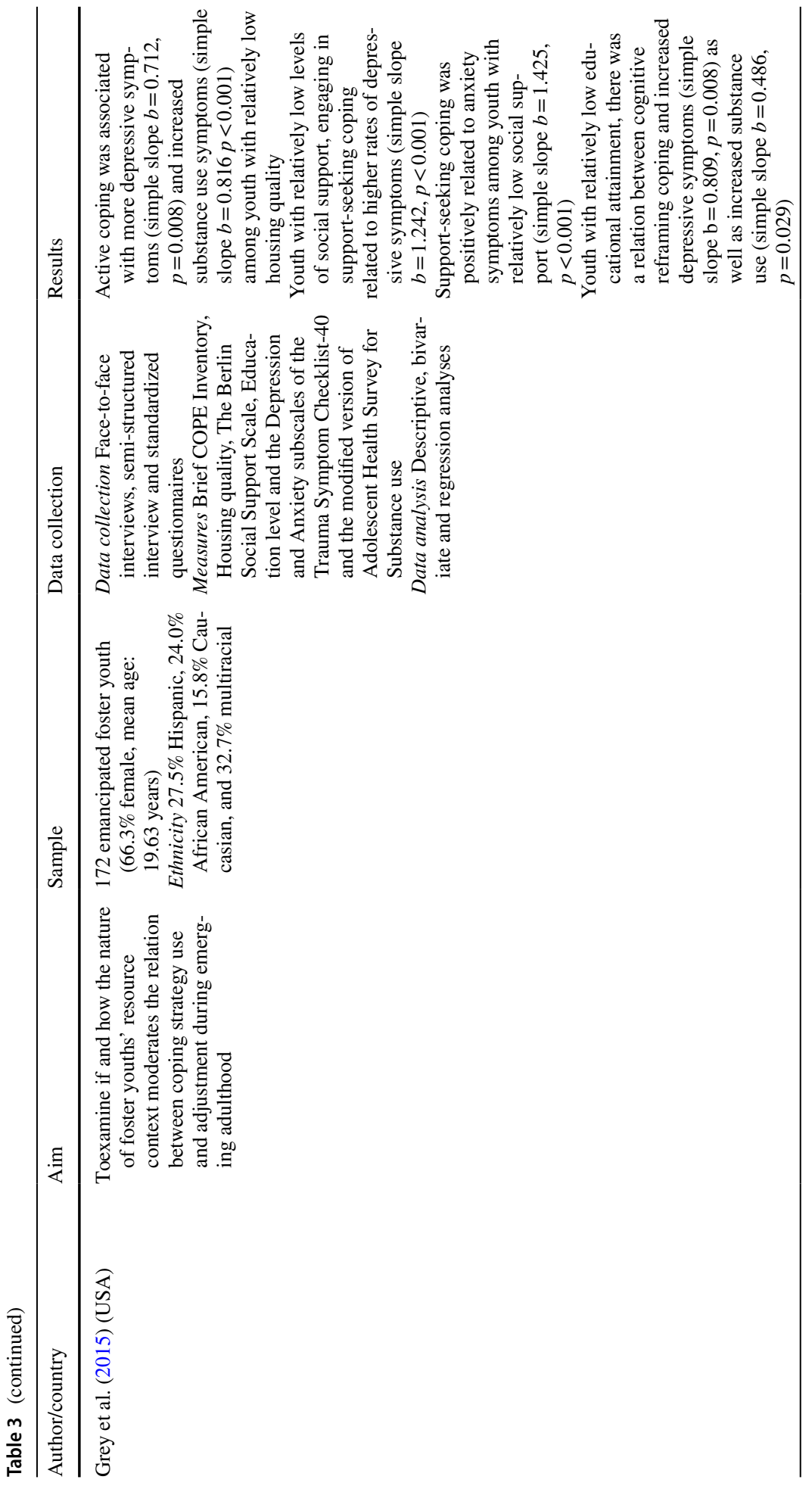




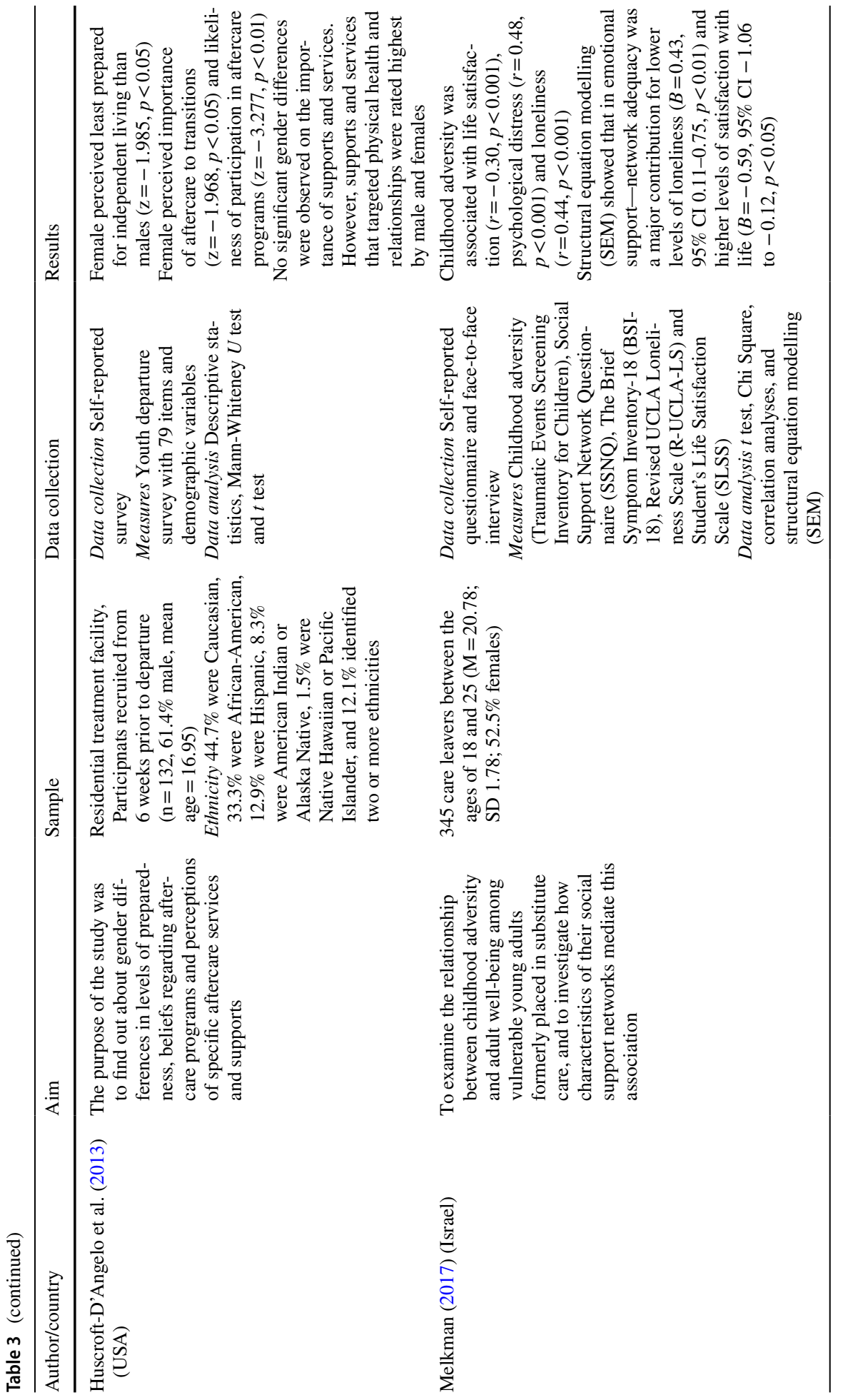




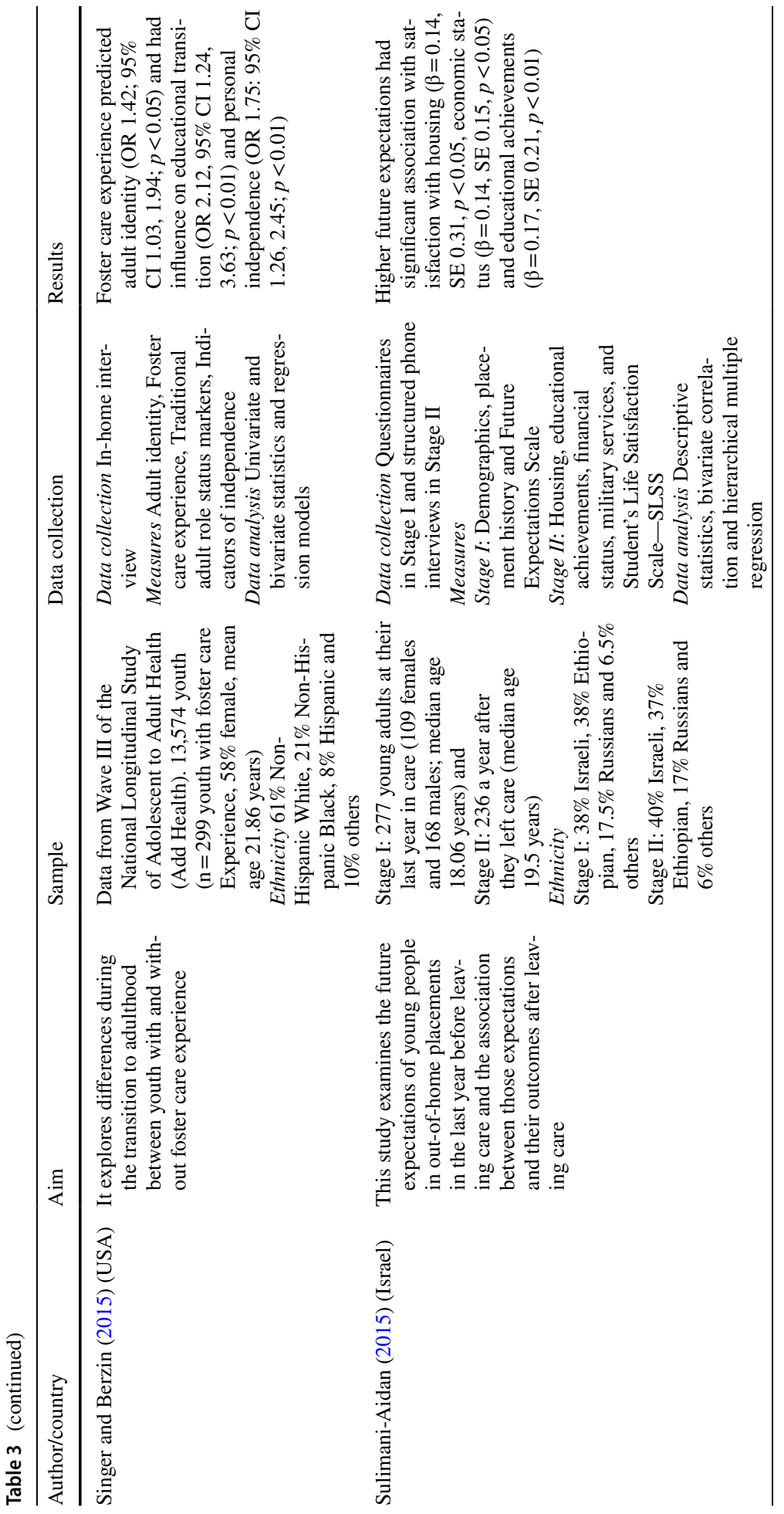




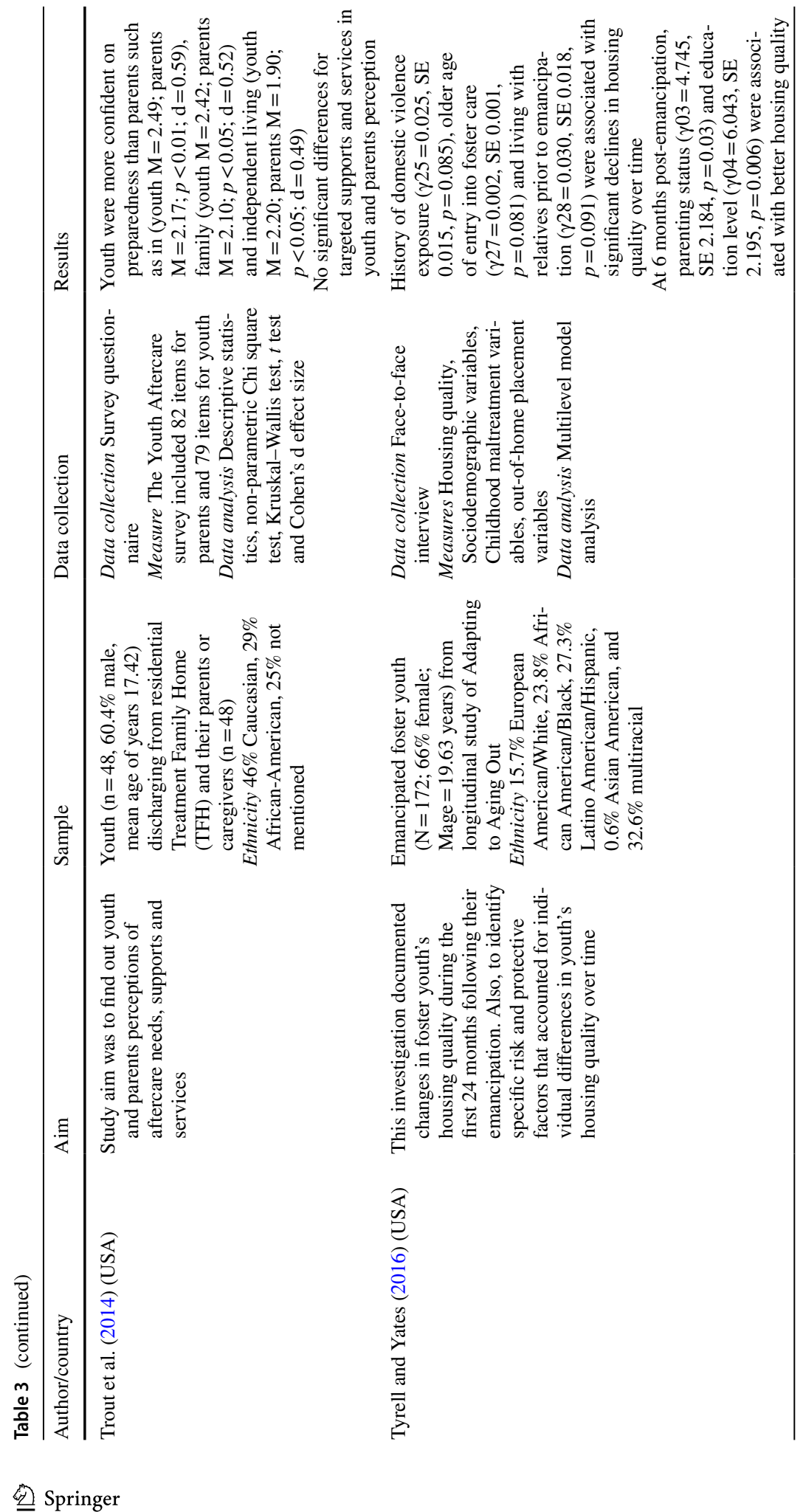




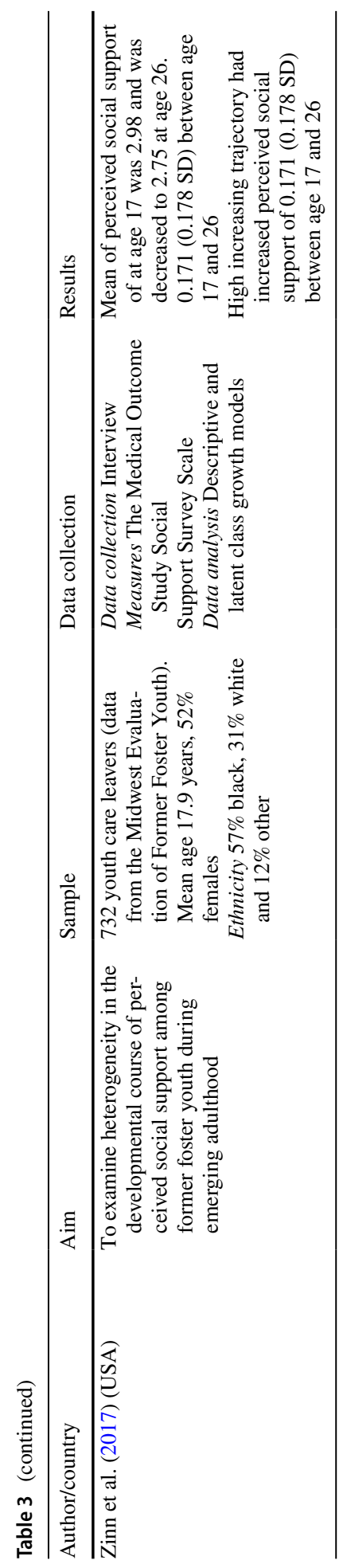


Melkman 2017; Sulimani-Aidan 2015; Trout et al. 2014), and one study utilized life history calendar techniques (Fowler et al. 2011).

\section{Preparedness for Independent Living}

Care leavers' perceptions and experiences of their preparedness for independent living were reported in nine studies. The themes found that described preparedness for independent living were: care leavers' identity (Singer and Berzin 2015), their abilities (Casey et al. 2010; Dinisman and Zeira 2011; Dutta 2017; Huscroft-D'Angelo et al. 2013; Melkman 2017; Trout et al. 2014; Zinn et al. 2017) and future plans (Casey et al. 2010; Dutta 2017; Sulimani-Aidan 2015). Foster care experience significantly predicted adult identity. Young people who had foster care experience were more often parents themselves, and had a poorer school attendance record compared to youth without foster care experience. It was more likely that they felt more like an adult all of the time and rated themselves more independent compared to non-foster youth (Singer and Berzin 2015).

Young people leaving foster care perceived themselves as having an average or high ability to engage in self-determined behaviors such as daily living, arranging housing and money management. They also perceived themselves as having social support available from family, partner and friends 'most of the time' (Casey et al. 2010; Dinisman and Zeira 2011; Dutta 2017; Huscroft-D’Angelo et al. 2013; Melkman 2017; Zinn et al. 2017). The most important significant other was a mother (Casey et al. 2010). Peer and staff support positively affected readiness for independent living, while parents' or other close relatives' support or participation in the programs for independent living did not contribute (Dinisman and Zeira 2011).

In general, there were no significant differences in preparedness between males and females (Casey et al. 2010; Dinisman and Zeira 2011; Huscroft-D'Angelo et al. 2013). In Huscroft-D'Angelo et al.'s (2013) study males' and females' perceptions differed to some extent. Males felt the most prepared with regard to relationships, while females felt most prepared in terms of their physical health. Also, males felt least prepared for community involvement, while females indicated being least prepared for independent living. The youths own perceptions did not deviate significantly from their teachers' opinions (Casey et al. 2010). Readiness for higher education was rated the lowest (Dinisman and Zeira 2011). In Trout et al.'s (2014) study parents were significantly less confident in the youths' preparedness than the youth themselves in three areas: relationships, family and independent living. Both sides indicated similar perceptions regarding the level of preparedness in education, community involvement, physical health and mental health.

While most of the care leavers were aware of the process of leaving care beforehand, few were able to participate in the planning of their departure (Dutta 2017). Youths presented a medium level of hopefulness, which suggests that they had average persistence and skills for problem solving (Casey et al. 2010). Overall, preparedness for independent living was mostly explained by care leavers' self-esteem and working situation (Dinisman and Zeira 2011; Dutta 2017).

The young people were quite confident about their future achievements across a range of life domains (Casey et al. 2010; Dutta 2017; Sulimani-Aidan 2015). In Sulimani-Aidan's (2015) study 80-90\% of the young people were confident of landing a good job, having a car, an apartment and good friends and a stable and happy marriage. About $70 \%$ thought that they would have an important place in the community. Nevertheless, one-quarter 
Table 4 Themes explaining transition to adult life

\begin{tabular}{ll}
\hline Themes & Specified in the articles \\
\hline $\begin{array}{l}\text { Care leavers' life history } \\
\text { and personal character- } \\
\text { istics }\end{array}$ & Childhood exposure to domestic violence (Melkman 2017; Tyrell and Yates \\
& Self-esteem (Dinisman and Zeira; Dutta 2017) \\
& Positive future expectations (Sulimani-Aidan 2015) \\
& Abilities for goal achievement (Dutta 2017; Huscroft-D'Angelo et al. 2013) \\
& Happiness (Dutta 2017) \\
& Educational level (Fowler et al. 2011; Grey et al. 2015; Singer and Berzin \\
& 2015; Trout et al. 2014) \\
& Mental health (Fowler et al. 2011) \\
& Success of attaining adulthood (Courtney et al. 2012) \\
& Perceived better preparation of leaving care (Dutta 2017) \\
& Older age of entry into foster care (Tyrell and Yates 2016) \\
& Leaving care at an older age (Dutta 2017; Fowler et al. 2011) \\
& Marriage (Dutta 2017) \\
& Peer support and staff support (Casey et al. 2010; Dinisman and Zeira 2011) \\
Soster care specific features & Satisfaction with support (Grey et al. 2015; Melkman 2017; Zinn et al. 2017) \\
& Perceived network adequacy (Melkman 2017) \\
& Employment (Dutta 2017; Fowler et al. 2011) \\
Housing quality (Fowler et al. 2011; Grey et al. 2015) & \\
Prerequisites for safe life & \\
&
\end{tabular}

thought that they would not attain a higher education and would not be able to provide a good life for their children. In Dutta's (2017) study more than two-thirds of the girls had goals which they wanted to pursue and achieve, and they had made plans to do so. However, only $18 \%$ perceived that they could achieve these ambitions, and many had given up altogether. Half of the girls had a bright future view; less (31\%) were satisfied with their future prospects. In Sulimani-Aidan's (2015) study a small percentage of the young people had negative future expectations. For example, $10 \%$ thought or were sure that they would get involved with law enforcement; $20 \%$ thought or were sure that they would be unemployed; and $15 \%$ thought or were sure that they would have mental health difficulties in the future. Almost half of the youth planned to live with their birth parents after departure, with only $4 \%$ planning to live alone (Casey et al. 2010). Almost all planned on graduating from high school. A majority of the youth did not specify what kind of plans they had for further education after high school. Most of the youth planned on seeking either part-time (40\%) or full-time (40\%) employment; however, $20 \%$ were undecided (Casey et al. 2010).

\section{Support Needs for Preparation to Adulthood}

Support needs for preparing for the transition to adulthood were described in two articles (Huscroft-D'Angelo et al. 2013; Trout et al. 2014). A majority of both youth and their parents felt that a transition plan would be very helpful, and more than half of the parents and one-quarter of young people would be very likely to participate in an aftercare program (Trout et al. 2014). Females reported being more willing to participate in the programs than males (Huscroft-D'Angelo et al. 2013). During the transition period, both male and female care leavers regarded the support and services related to physical health and relationships as more important than the support that covered the domains of mental health and community involvement (Huscroft-D'Angelo et al. 2013; Trout et al. 2014). The opinions of 
youths and their parents did not differ significantly, although parents also emphasized support and services targeting education (Trout et al. 2014). Males rated the most important support and services as those that helped in the development of money management skills and positive relationships with family members and caregivers; assistance with enrolling in the military and accessing mental health and transportation services were regarded as least important (Huscroft-D’Angelo et al. 2013). Females felt that assistance with enrolling in school and developing homework routines and positive family relationships to be the most important support or services that they needed. Of less importance for them was support with enrolling in the military, joining parent support groups and managing medication for behavior or mental health (Huscroft-D'Angelo et al. 2013).

\section{Coping with Independent Living}

Coping with independent living was reported in eight studies, and the themes describing it were: satisfaction with coping (Dutta 2017; Sulimani-Aidan 2015); the challenges of coping (Casey et al. 2010; Dutta 2017; Melkman 2017; Sulimani-Aidan 2015; Zinn et al. 2017); coping strategies (Grey et al. 2015); and coping profiles (Courtney et al. 2012; Fowler et al. 2011). About 40-60\% of the young people who had lived on their own were happy with their coping, comfortable in their present homes and satisfied with their lives (Dutta 2017; Sulimani-Aidan 2015). Even more (about 80-90\%) former foster care girls were able to take care of themselves when faced with occasional health problems, maintaining their sexual health, avoiding using tobacco, alcohol and drugs and managing their own budget (Dutta 2017). A majority of the girls were happy in their marriages and in their relationships with family members and friends (Dutta 2017). Sulimani-Aidan (2015) found that positive future expectations were statistically significantly related to satisfaction with housing, educational achievement and financial status. Marriage, happiness, self-esteem, leaving care at an older age, comfortable accommodation, good support networks, educational qualifications and working were significantly associated with positive coping with independent living (Dutta 2017). The girls who perceived themselves to be better prepared to leave care and perceived their abilities in goal achievements as higher than the other care leavers, had positive experiences after leaving care (Dutta 2017) (Table 4).

Young people predicted that when leaving care the biggest challenges they would face were connected with the influence of peers on their behavior choices, finding employment, attending school and getting along with parents and siblings (Casey et al. 2010). The biggest challenges that they had faced during their first years after departure were adjustment to military service, graduating with a high school diploma, having a stable income and savings and having a person with whom to share their problems and get help (Dutta 2017; SulimaniAidan 2015). The perceived high level of social support on exiting foster care gradually, but modestly, decreased during the first few years after foster care. Youth who reported relatively high levels of social support at the exit point were much more likely to perceive higher levels of support when they were living on their own than other youth (Zinn et al. 2017). Former foster youths' social support development varied, and the differences in social support that existed at the departure from aftercare appeared to become more evident over time (Melkman 2017; Zinn et al. 2017). Melkman (2017) noticed that network adequacy was consistently the one attribute most closely related to psychological distress, loneliness and poor life satisfaction. For example, for emotional support, more incidences of adversity predicted lower levels of perceived network adequacy, satisfaction with support and frequency of contact with 
supporters. In turn, perceived network adequacy, satisfaction with support and frequency of contact positively contributed to life satisfaction and to lower levels of loneliness (Table 4).

Grey et al. (2015) identified active, support-seeking and cognitive reframing coping strategies among emancipated foster youth. Coping strategies were moderated by housing quality, social support and educational level and were related to depression, anxiety and substance use. Even in the presence of positive strategies there may be associations with problematic adaptation during emerging adulthood in the absence of the requisite resources to control the stressor effectively. For example, an active coping strategy was associated with more depressive symptoms and substance use among young people who reported relatively poor housing quality than among those who reported active coping in the presence of higher housing quality. Similarly, the interaction between educational attainment and cognitive reframing coping suggested that this coping strategy may be associated with increased depressive symptomatology and substance use if employed by youth with relatively few educational resources (Grey et al. 2015). Tyrell and Yates (2016) found that transition-aged female foster youth, parenting youth, youth with a high school degree and youth who became emancipated at older ages had higher housing quality after care. Childhood exposure to domestic violence, an older age of entry into foster care and placement with a relative just prior to emancipation were all risk factors that resulted in youths living in lower housing quality (Table 4).

Fowler et al. (2011) also found that former foster youth's coping strategies differed when it came to housing, education, employment and mental health. They labeled youth as stableengaged [which formed the biggest group (41\%)], stable-disengaged (30\%) and instable-disengaged (29\%). On the other hand, Courtney et al. (2012) categorized former foster youth into four profiles based on the success they made in the typical markers of attaining adulthood. Their categories were accelerated adults (36\%), struggling parents (25\%), emerging adults (21\%) and troubled or troubling youth (17\%). Stable-engaged and accelerated adults had succeeded in their coping in the same way. During follow-up they later reported periods of stable housing and parenthood. Half of them were living on their own, most youths had graduated from high school and almost all were employed after the follow-up period. Stabledisengaged youths had similarly stable housing across the follow-up period, but only a few lived independently; one-third had earned a high school diploma and almost $79 \%$ were unemployed after the follow-up period. The life situation of struggling parents resembled stable-disengaged youths' life situations. In addition to Fowler et al.'s (2011) description, Courtney et al. (2012) reported that struggling parents were most likely to have a partner and be parenting in demanding circumstances. They were most likely to be in receipt of need-based government benefits, and they also reported the lowest levels of social support. Instable-disengaged and troubled or troubling youths also had similarities in their life situation. They reported chronic housing instability, low levels of education, interrupted education, unemployment, poor mental health, substance abuse and the lowest levels of social support and the highest rates of victimization compared to the other groups. Youths who were younger at the point of exit from foster care were more likely to be in the instable-disengaged class. The transition markers (e.g. living on their own; finishing school; having children) of emerging adults (21\%) were noticeably delayed. 


\section{Discussion}

\section{Consideration of Results}

The results as they relate to the first research question indicate that most of the care leavers felt themselves prepared for adult life. Most of them had optimistic views of their ability to live independently and their future expectations were positive - they recognized themselves as adults. Hard childhood experiences and separation from the birth family had forced them to grow up early and fast. Young people without foster care experience, in contrast, can grow up gradually. The hopefulness of care leavers when thinking about adult life very much belongs to youth and is a source of resilience and self-confidence. It is an inner strength that may help in problem-solving and coping. This overview gives a more optimistic picture of care leavers' preparedness for adult life than the qualitative systematic reviews (Häggman-Laitila et al. 2018; Parry and Weatherhead 2014). The Midwest study pointed out that care leavers do not feel prepared while making the transition to adulthood and reported them needing more help than they were offered (Courtney et al. 2011). The results of this review lead us to ask, are care leavers overestimating their abilities as Casey et al. (2010) suggest? The care leavers that participated in the original quantitative studies had experience of living alone. Their perceptions might, therefore, be realistic, yet perceptions of preparedness for adult life were ambiguous. For example, care leavers believe that they will have an important place in society although they regarded community involvement as one of the most difficult issues to deal with. Care leavers had settled goals in various life domains, but they were not convinced that they could achieve them. These examples lead us to ask how we might help young people to identify and address this kind of discrepancy. These results highlight the importance of discussions with care leavers on their individual assumptions of their preparedness. The task of the professional-not always fulfilled-is to help young people to find ways to realize their goals and solve their problems: care leavers should be met and heard as individuals during their transition process to adult life. Qualitative systematic reviews (Häggman-Laitila et al. 2018; Parry and Weatherhead 2014), which offer information about care leavers' experiences of their identity and emotions, support this rather regrettable conclusion. Care leavers report that they are not involved in shaping their transition process and the interaction with professionals is not always supportive.

Only two studies were found concerning the care leavers' support needs in the transition phase to adult life. The results pertaining to the second research question emphasize the importance of relationships in the lives of these youngsters. Although they perceive that they had relatively good abilities in this life domain, they wanted to improve them further. Other support needs that were mentioned above others dealt with physical health, money management skills and attending school. Of less importance were support for mental health and community involvement. These results are surprising as mental health problems are common among care leavers (Courtney et al. 2010; Fowler et al. 2009; Gypen et al. 2017; Havlicek et al. 2013) and it is a well-known fact that care leavers underuse these services (Jones et al. 2011; McMillen and Raghavan 2009). To understand this paradox more deeply, further research is needed. The qualitative systematic review (Häggman-Laitila et al. 2018) revealed that the transition process was poorly prepared and focused mostly on sexual health. These results underline the need to develop services during the transition phase to adult life. Care leavers have positive attitudes toward support programs, but they are not as eager to participate as their parents (although they identify their support needs). The reasons for this are not well understood and we need further investigation in this area. 
It will be recalled that our third research question addressed coping. The results revealed that understanding the coping mechanisms of care leavers is a complex issue which depends on comprehending the interaction of different life domains. Care leavers had different coping strategies and profiles, and these should be noted by professionals assisting in the preparation for adult life. The results on coping strategies of this review pointed out the importance of the requisite material resources for a safe life. If housing quality, social support or educational achievements are poor, positive coping strategies alone are not enough to alleviate stress. Helping care leavers to have stable housing and employment status might improve their coping strategies. However, higher levels of education are related to higher earnings, and therefore supporting care leavers in higher education is another potentially useful approach (Naccarto et al. 2010). Overall, care leavers experience remarkable difficulties in achieving a high school degree (Cameron et al. 2018; Gypen et al. 2017; Kääriälä and Hiilamo 2017), and according to this review care leavers themselves are fully aware of these challenges. Supportive programs for education and case management (Everson-Hock et al. 2011; Lawler et al. 2014; Murray and Goddard 2014) have succeeded in increasing participation in higher education and working life. Successful support programs require a holistic approach with sufficient attention paid to education, interprofessional collaboration and the involvement of care leavers with their transition planning. Qualitative systematic reviews (Häggman-Laitila et al. 2018; Parry and Weatherhead 2014) also underlined this need for a holistic and personalized approach. Service systems are fragmented and the challenges for interprofessional collaboration are obvious. However, whatever the difficulties the needs of these young people should be prioritized when seeking to develop interprofessional collaboration.

This review provided information about the factors that impact on the transition to adult life and subsequent coping — care leavers' personal characteristics, care-specific features, education, the prerequisites for a safe life and social support. Previous studies have reported similar results (Dumaret et al. 2011; Lawler et al. 2014). The acknowledgement of these factors is useful in assessing care leavers' capabilities in the transition phase and they should also be taken into account when planning for personalized support. However, it is worthwhile highlighting that the research results looking at these factors are still sporadic, and more studies are needed to establish reliable recommendations for development of the services.

\section{Implications for Policy, Practice and Future Research}

This review highlighted that the successful transition process for care leavers moving to adult life is based on the identification of young people's perceptions of their preparedness, their support needs in different life domains and coping strategies and profiles. In addition, care leavers expected to have continuous support on maintaining their physical health, relationships, education and financial management. Interventions that incorporate these issues along with consideration for care leavers' strengths and coping skills might help for successful transition. For example, YVLifeSet program plans services according to the needs and goals of vulnerable young adults and assists once a week for about 9-12 months (Manno et al. 2014). The evaluation of this program indicated positive impacts on incomes and employment, stable housing, economic hardship, and health and safety. However, there were no impacts on social support (Courtney et al. 2019). Therefore, as suggested by Blakeslee (2012), future research on social network analysis is warranted for developing effective interventions for youth in foster care for their transition to independent living. 
In addition, full preparedness is based on young people's realistic perceptions of their identity, abilities, emotions and future wishes. These aspects are well identified in quantitative and qualitative studies, yet these studies still produce hardly any knowledge of young people's strengths. This serious shortcoming should be addressed in future studies. Support for the transition to adult life should also take into account a preventive approach; care leavers need tailored advice about how they can preserve their hopefulness, utilize their abilities, strengthen their self-confidence and build the support networks that will help them achieve the prerequisites for a safe life when facing the challenges of adulthood. It seems that care leavers' individuality is poorly acknowledged in the services. Therefore, it is important to assess the life skills of these youths. In United States, Ansell-Casey Life Skills Assessment has been used widely to measure the developmental needs of youth (Nollan et al. 2001). Utilizing such tool in different cultures can help to identify different support needs, coping strategies and profiles. The differences between male and female care leavers also need to be taken into consideration. The complexity of the support needs in the transition phase and coping with independent living need a holistic, personalized approach and interprofessional collaboration. These aspects are of great importance and they should guide the development of interventions for care leavers. Future research should be targeted at the involvement of care leavers in their own care. At the policy level, it is worth investing in these young people, as the aftercare phase is the final stage of the service system and the prevention of complicated and ultimately damaging problems is still possible.

\section{Strengths and Limitations}

To ensure that the search process was both systematic and extensive, it was carried out with the help of an information specialist from a library and by utilizing database directories. Search terms were carefully chosen to produce a wide range of results focused on the transition from foster care, taking into account the word indexes and special features of the databases. These were reported accurately to ensure repeatability. Two researchers worked independently to select the papers for consideration, but the selection process and ambiguous cases were discussed together, which added to the reliability of the data. The papers were initially chosen based on their titles and abstracts, and therefore it was possible that some studies may have been left out.

Relevant information about the original studies was meticulously documented in a matrix, and careful use of this information in the analysis increased the reliability of the review. The original studies described the transition to independent living from various perspectives and cultural contexts and using different kinds of measurements. The results were heterogeneous which limited the synthetization of the results. In spite of this, repeatability was achieved in the analysis, and it may be assumed that constructing essential conceptual categories was successful (Centre for Reviews and Dissemination 2009). The analyzed papers have been listed, and readers may therefore verify the reported classifications if they wish. The overall methodological strength of the studies in the review was evaluated using the Centre for Evidence Based Management's (2014) criteria for a cross-sectional study and it was deemed robust. This further enhances the validity of the review. However, the studies were descriptive and therefore the evidence remains limited. In addition, grey literature was not searched because of the restricted resources for conducting the review, and this may have increased the likelihood of bias in the acquisition of material for the review. 


\section{Conclusions}

Many foster care leavers identified themselves as adults, and were quite confident about their future and potential for independent living. They had positive attitudes toward support services programs but were reluctant to participate in them. They had different coping strategies and profiles but often faced challenges in finding employment, opportunities in education and having a person to rely on. Factors that support the transition to independent living included care leavers' personal characteristics, certain care-specific features, a good education, sufficient prerequisites for a safe life and strong social support networks. In spite of the vulnerability of care leavers, they are often hopeful and demonstrate various abilities and strengths to cope with independent living. Support for the transition to adult life should be based on a preventive and personalized approach. Care leavers need advice on how they can preserve their sense of hope, utilize their innate abilities, strengthen their self-confidence and support networks and achieve the prerequisites for a safe life when facing the challenges of adulthood. Despite approaching the research theme from different conceptual perspectives, cultural contexts and using different measurements, the body of evidence in this field remains insubstantial. In consequence, we are certain that further studies are needed to provide more reliable and extensive evidence-based recommendations to inform service development, staff education and research activities in this important area.

Acknowledgements Open access funding provided by University of Eastern Finland (UEF) including Kuopio University Hospital.

Funding This work was supported by the government's funding for health research at the university level (VTR/ERVA, HEL 2014-007660) and the City of Helsinki, Department of Social Services and Health Care.

\section{Compliance with Ethical Standards}

Conflict of interest The authors declare that they have no conflict of interest.

Ethical Standard This article does not contain any studies with human participants performed by any of the authors.

Open Access This article is distributed under the terms of the Creative Commons Attribution 4.0 International License (http://creativecommons.org/licenses/by/4.0/), which permits unrestricted use, distribution, and reproduction in any medium, provided you give appropriate credit to the original author(s) and the source, provide a link to the Creative Commons license, and indicate if changes were made.

\section{References}

\section{Included studies are denoted by asterisk mark}

Berlin, M., Vinnerljung, B., \& Hjern, A. (2011). School performance in primary school and psychosocial problems in young adulthood among care leavers from long-term foster care. Children and Youth Services Review, 33(12), 2489-2497. 
Blakeslee, J. (2012). Expanding the scope of research with transition-age foster youth: Applications of the social network perspective. Child and Family Social Work, 17(3), 326-336.

Cameron, C., Holligsworth, K., Shcoon, I., van Santen, E., Schröer, W., Ristikari, T., et al. (2018). Care leavers in early adulthood: How do they fare in Britain, Finland and Germany. Children and Youth Services Review, 87, 163-172.

*Casey, K. J., Reid, R., Trout, A. L., Hurley, K. D., Chmelka, M. B., \& Thompson, R. (2010). The transition status of youth departing residential care. Child \& Youth Care Forum, 39(5), 323-340.

Center for Evidence-Based Management. (2014). Critical appraisal checklist for cross-sectional study. Resource document. https://www.cebma.org/wp-content/uploads/Critical-Appraisal-Questions-fora-Cross-Sectional-Study-july-2014.pdf. Accessed 14 June 2018.

Centre for Reviews and Dissemination. (2009). Systematic reviews. York: Centre for Reviews and Dissemination, University of York.

Courtney, M. E., Dworsky, A., Lee, J. S., \& Raap, M. (2010). Midwest evaluation of the adult functioning of former foster youth: Outcomes at age 23 and 24. Chicago: Chapin Hall at the University of Chicago.

*Courtney, M. E., Hook, J. L., \& Lee, J. S. (2012). Distinct subgroups of former foster youth during young adulthood: Implications for policy and practice. Child Care in Practice, 18(4), 409-418.

Courtney, M. E., Lee, J., \& Perez, A. (2011). Receipt of help acquiring life skills and predictors of help receipt among current and former foster youth. Children and Youth Services Review, 33(12), 2442-2451.

Courtney, M. E., Valentine, E. J., \& Skemer, M. (2019). Experimental evaluation of transitional living services for system-involved youth: Implications for policy and practice. Children and Youth Services Review, 96, 396-408.

*Dinisman, T., \& Zeira, A. (2011). The contribution of individual, social support and institutional characteristics to perceived readiness to leave care in Israel: An ecological perspective. British Journal of Social Work, 41(8), 1442-1458.

Dumaret, A. C., Donati, P., \& Crost, M. (2011). After a long-term placement: Investigating educational achievement, behaviour, and transition to independent living. Children and Society, 25(3), 215-227.

*Dutta, S. (2017). Life after leaving care: Experiences of young Indian girls. Children and Youth Services Review, 73, 266-273.

Everson-Hock, E. S., Jones, R., Guillaume, L., Clapton, J., Duenas, A., Papaioannou, D., et al. (2011). Supporting the transition of looked-after young people to independent living: A systematic review of interventions and adult outcomes. Child: Care, Health and Development, 37(6), 767-779.

Fowler, P. J., Toro, P. A., \& Miles, B. W. (2009). Pathways to and from homelessness and associated psychosocial outcomes among adolescents leaving the foster care system. American Journal of Public Health, 99(8), 1453-1458.

*Fowler, P. J., Toro, P. A., \& Miles, B. W. (2011). Emerging adulthood and leaving foster care: Settings associated with mental health. American Journal of Community Psychology, 47, 335-348.

*Grey, I. K., Berzenski, S. R., \& Yates, T. M. (2015). Coping in context: associations between resource availability and coping effectiveness among emancipated foster youth. Emerging Adulthood, 3(5), 295-305.

Gypen, L., Vanderfaeillie, J., De Meayer, S., Belenger, L., \& Van Holenm, F. (2017). Outcomes of children who grew up in foster care: Systematic review. Children and Youth Services Review, 76, 74-83.

Häggman-Laitila, A., Salokekkilä, P., \& Karki, S. (2018). Transition to adult life of young people leaving foster care: A qualitative systematic review. Children and Youht Services Review, 95, 134-143.

Havlicek, J. R., Garcia, A. R., \& Smith, D. C. (2013). Mental health and substance use disorders among foster youth transitioning to adulthood: Past research and future directions. Children and Youth Services Review, 35, 194-203.

Hiles, D., Moss, D., Wright, J., \& Dallos, R. (2013). Young people's experience of social support during the process of leaving care: A review of the literature. Children and Youth Services Review, 35(12), 2059-2071.

*Huscroft-D’Angelo, J., Trout, A., Epstein, M., Duppong-Hurley, K., \& Thompson, R. (2013). Gender differences in perceptions of aftercare supports and services. Children and Youth Services Review, 35(5), 916-922.

Jones, R., Everson-Hock, E. S., Papaioannou, D., Guillaume, L., Goyder, E., Chilcott, J., et al. (2011). Factors associated with outcomes for looked-after children and young people: A correlates review of the literature. Child: Care, Health and Development, 37(5), 613-622.

Keller, T. E., Cusick, G. R., \& Coutrney, M. E. (2007). Approaching the transition to adulthood: Distinctive profiles of adolescents aging out of the child welfare system. Social Service Review, 81(3), 453-484. 
Kääriälä, A., \& Hiilamo, H. (2017). Children in out-of-home care as young adults: A systematic review of outcomes in the Nordic countries. Children and Youth Services Review, 79, 107-114.

Lawler, M. J., Sayfan, L., Goodman, G. S., Narr, R., \& Gordon, I. R. (2014). Comprehensive residential education: A promising model for emerging adults in foster care. Children and Youth Services Review, $38,10-19$.

Manno, M., Jacobs, E., Alson, J., \& Skemer, M. (2014). Moving into adulthood: Implementation findings from the youth villages transitional living evaluation. New York: MDRC.

McMillen, J. C., \& Raghavan, R. (2009). Pediatric to adult mental health service use of youth in the foster care system. Journal of Adolescent Health, 44(1), 7-13.

* Melkman, E. P. (2017). Childhood adversity, social support networks and well-being among youth aging out of care: An exploratory study of mediation. Child Abuse and Neglect, 72, 85-97.

Moher, D., Liberati, A., Tetzlaff, J., \& Altman, D. G. (2009). Preferred reporting items for systematic reviews and meta-analyses: The PRISMA statement. BMJ. https://doi.org/10.1136/bmj.b2535.

Murray, S., \& Goddard, J. (2014). Life after growing up in care: Informing policy and practice through research. Australian Social Work, 67(1), 102-117.

Naccarto, T., Brophy, M., \& Courtney, M. E. (2010). Employment outcomes of foster youth: The results from the Midwest evaluation of the adult functioning of foster youth. Children and Youth Services Review, 32, 551-559.

Nollan, K. A., Horn, M., Downs, A. C., Pecora, P. J., \& Bressani, R. V. (2001). Ansell-Casey Life Skills Assessment (ACLSA) and life skills guidebook manual. Seattle, WA: Casey Family Programs.

Parry, S., \& Weatherhead, S. (2014). A critical review of qualitative research into the experiences of young adults leaving foster care services. Journal of Children's Services, 9(4), 263-279.

Paulsen, V., \& Berg, B. (2016). Social support and interdependency in transition to adulthood from child welfare services. Children and Youth Services Review, 68, 125-131.

Rutman, D., \& Hubberstey, C. (2016). Is anybody there? Informal supports accessed and sought by youth from foster care. Children and Youth Services Review, 63, 21-27.

*Singer, E. R., \& Berzin, S. C. (2015). Early adult identification among youth with foster care experience: Implications for emerging adulthood. Journal of Public Child Welfare, 9(1), 65-87.

Stein, M. (2006). Research review: Young people leaving care. Child and Family Social Work, 11(3), 273-279.

*Sulimani-Aidan, Y. (2015). Do they get what they expect? The connection between young adults' future expectations before leaving care and outcomes after leaving care. Children and Youth Services Review, $55,110-117$.

*Trout, A. L., Hoffman, S., Huscroft-D’Angelo, J., Epstein, M., Duppong-Hurley, K., \& Stevens, A. L. (2014). Youth and parent perceptions of aftercare supports at discharge from residential care. Child and Family Social Work, 19(3), 304-311.

*Tyrell, F. A., \& Yates, T. M. (2016). A growth curve analysis of housing quality among transition-aged foster youth. Child \& Youth Care Forum, 46(1), 91-117.

*Zinn, A., Palmer, A. N., \& Nam, E. (2017). Developmental heterogeneity of perceived social support among former foster youth. Children and Youth Services Review, 76, 51-58.

Publisher's Note Springer Nature remains neutral with regard to jurisdictional claims in published maps and institutional affiliations. 